\title{
Isosteric design of friction-reduction and anti-wear lubricant additives with less sulfur content
}

\author{
Xinlei GAO ${ }^{1, *}$, Denghui LIU $^{1}$, Ze SONG $^{1}$, Kang DAI ${ }^{2}$ \\ ${ }^{1}$ School of Chemical and Environmental Engineering, Wuhan Polytechnic University, Wuhan 430023, China \\ ${ }^{2}$ College of Pharmacy, South-Central University for Nationalities, Wuhan 430074, China \\ Received: 18 January 2017 / Revised: 15 March 2017 / Accepted: 10 April 2017 \\ (C) The author(s) 2017. This article is published with open access at Springerlink.com
}

\begin{abstract}
To reduce harmful sulfur content in lubricant additives, making use of isosterism has been shown to be an effective strategy. When thiobenzothiazole compounds were used as templates, the exchange of sulfur atoms in the thiazole ring with oxygen atoms and $\mathrm{NH}$ groups produced twelve isosteres. Similarly, 2-benzothiazoleS-carboxylic acid esters were used as template molecules to produce six isosteres. About $30 \%$ of the isosteres exhibited a satisfactory deviation of $\pm 5 \%$ relative to the template, ignoring the specific changes in the base oils, the differences in molecular structure, and the friction or wear properties. The template molecules and isosteres in triisodecyl trimellitate exhibited better tribological properties than in trimethylolpropane trioleate or bis(2ethylhexyl) adipate. Comparative molecular field analysis (CoMFA)- and comparative molecular similarity index analysis (CoMSIA)-quantitative structure tribo-ability relationship (QSTR) models were employed to study the correlation of molecular structures between the base oils and additives. The models indicate that the higher the structural similarities of the base oils and additives are, the more synergetic the molecular force fields of the lubricating system are; the molecular force fields creating synergistic effects will improve tribological performance.
\end{abstract}

Keywords: isosterism; friction-reduction and anti-wear lubricant additives; comparative molecular field analysis; comparative molecular similarity index analysis; quantitative structure tribo-ability relationship; less sulfur content

\section{Introduction}

The largest user of lubricant additives is the automotive industry. Over the past ten years, the development of lubricant additives has been affected by new laws and regulations. In order to control pollution, European and American countries have enacted stringent new emission standards that require an extended life for exhaust systems, improved fuel efficiency, and the use of less toxic biodegradable lubricants with acceptable environmental compatibility. The new specified limits of sulfated ash, phosphorous, and sulfur in lubricants are lower than previously defined ones [1]. These limits now require adjusting and improving engine oil formulations, the gradual introduction of ash-less antioxidants, anti-wear additives, and enhancements in dispersant and viscosity indices. To effectively reduce environmental pollution, lubricants having high-performance friction-reduction and anti-wear additives with less sulfur content need to replace the widely used additives having high sulfur content.

Sulfur, which plays an important role, is difficult to replace in the development of new lubricants with adequate friction reduction and anti-wear properties [2-9]. A traditional research and development approach would have an enormous workload and high costs. There have been few successful systematic theoretical and experimental reports on new lubricant additives that employ little or no sulfur. Hence, to meet the environmental protection requirements, a new

* Corresponding author: Xinlei GAO, E-mail: gaox10131@163.com 
isosterism concept is introduced in this paper [10-12] for the design of new lubricant additives with less sulfur, which is based on selected template molecules.

The concept of chemical isosteres [13, 14] was first discussed by Langmuir in 1919, who revealed that atoms, functional groups, and molecules with similar molecular electronic structures exhibit similar physical and chemical properties [15]. These similarities often occur for atoms that are in the same column in the periodic table - the column with atoms having the same number of outer electrons or having similar sizes and properties or behaviors. In 1925, Grimm formulated the hydride displacement law [16]. In 1932, Erlenmeyer proposed a broadening of the term isosterism by defining isosteres as elements, molecules, or ions that have the same number of valence electrons [16]. In 1951, Friedman introduced the term bioisosterism for the similar or antagonistic biological activity of structurally related compounds [13, 14, 16]. In 1979, Thornber broadened the term bioisosteres to include subunits, groups, or molecules that possess physicochemical properties with similar biological effects $[13,14,16]$. In structure optimization research, bioisosterism is actively used for structural modification of drugs to replace isosteres with one another in the variable part of the basic molecular structure. The isosteres refer to atoms, ions, and molecules with the same number of outer electrons, as well as groups with similar steric and electronic configurations. Isosteres have groups or substituents with similar physical and chemical properties, resulting in similar, related, or opposing biological activities.

Burger classified and subdivided bioisosteres into two broad categories: classic and non-classic [17]. Atoms, molecular subunits, or functional groups of the same valence and ring equivalents are defined as classic bioisosteres. These include monovalent, divalent, or trivalent atoms or groups, tetra-substituted atoms, and ring equivalents. Atoms or functional groups of similar volumes, electronegativities, and stereochemical characteristics are non-classic bioisosteres. These include cyclic vs. non-cyclic, functional groups, and retro-isosterism. Bioisosteric replacement should be rigorously preceded by careful analyses of the following parameters: (a) size, volume, and electronic distribution of the atoms, or degree of hybridization, polarizability, bonding angles, and inductive and mesomeric effects; (b) lipidic and aqueous solubility, such as $\log P$ and $\mathrm{pKa}$; (c) chemical reactivity of the functional groups or bioisosteric structural subunits; and (d) conformational factors. Classic and non-classic bioisosteres possess variable parts of the basic structure of a drug, which can be modified to improve therapeutic effects and to reduce side effects. There is no regularity in pharmacological activity — bioisosterism is used to design new drugs, and the biological activity can be increased, weakened, or have an antagonistic effect. Bioisosterism is a useful way to discover new analogs of therapeutic innovations that are commercially attractive.

In this paper, we discuss isosterism as a strategy for molecular modification with the aim of synthesizing a new series of congener compounds for use as friction-reduction and anti-wear lubricant additives. We seek ways to substitute for sulfur present in high performance additives, and which have similar structure and function. In preliminary trials, thiobenzothiazole compounds and 2-benzothiazoleS-carboxylic acid esters were used as template molecules because they exhibit relatively good frictionreduction and anti-wear performance when using as lubricant additives [18-24, 27, 29]. Isosterism is a strategy for the rational design of new additive molecules, and can be applied via the molecular modification of template molecules. Because the sulfur atom $(\mathrm{S})$, the oxygen $(\mathrm{O})$, and the $\mathrm{NH}$ are classic isosteres with the same divalent group, the $\mathrm{O}$ atoms and $\mathrm{NH}$ groups can be used to replace the $\mathrm{S}$ atoms. Hence, a preliminary partial substitution of $S$ in the lubricant additives was performed to prepare isosteric molecules, and the tribological performances were characterized.

Previously, the authors of this paper studied the relationship between molecular structure and tribological properties of lubricant additives and/or base oils, developed the concept of a "quantitative structure tribo-ability relationship" (QSTR) [23-29], and built back propagation neural network (BPNN)-QSTR model [23-25], infrared vibration-based descriptor (EVA)-QSTR model [26], Bayesian regularization neural network (BRNN)-QSTR model [27], comparative molecular field analysis (CoMFA)-QSTR model, and 
comparative molecular similarity index analysis (CoMSIA)-QSTR model [28, 29]. In this paper, using isosterism as a strategy of molecular modification, similar structural characteristics are now being searched for, in order to build a new series of congener compounds for new lubricant additives. This is an important step in the development of specific molecular designs from early theoretical work.

In addition, the correlation of the structural similarities and tribological performance of the lubricant additive and base oil is discussed. CoMFA and CoMSIA methodologies will be employed to illustrate the interaction between the lubricant additive and base oil in detail.

\section{Materials and methods}

\subsection{Preparation of lubricant additives with less sulfur content [30]}

\subsubsection{Isosteres based on thiobenzothiazole}

Using thiobenzothiazole compounds (Fig. 1) as template molecules, isosteric exchanges were performed between bivalent groups, exchanging the $S$ in the thiazole ring with an $\mathrm{O}$ in the compound shown in Fig. 2 and a NH group as shown in Fig. 3. This overall exchange, which is illustrated in Fig. 4, is referred to as Scheme 1.<smiles>[R]c1nc2ccccc2s1</smiles>

Fig. 1 The structural formula of the compound.<smiles>[R]c1nc2ccccc2o1</smiles>

Fig. 2 The structural formula of the compound.<smiles>[R]c1nc2ccccc2[nH]1</smiles>

Fig. 3 The structural formula of the compound.<smiles></smiles>

Fig. 4 Scheme 1.

\subsubsection{Preparation of thiobenzothiazole compounds and isosteres}

The thiobenzothiazole compounds (Fig. 5) and twelve isosteres (Figs. $6 \& 7$ ) were synthesized based on the classic isosterism of bivalent groups.

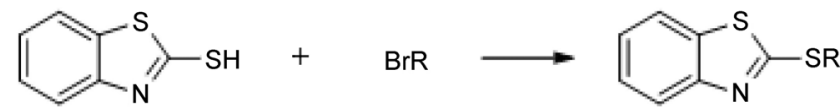

Fig. 5 Scheme 2.<smiles>[R7]c1nc2ccccc2o1</smiles>

Fig. 6 Scheme 3.<smiles>[R5]c1nc2ccccc2[nH]1</smiles>

Fig. 7 Scheme 4.

The template molecules and isosteres are shown in Table 1 .

\subsubsection{Isosteres based on 2-benzothiazole-S-carboxylic acid esters}

As shown above, the replacement of $\mathrm{S}$ in the thiazole ring in Scheme 5 (Fig. 8) present in 2-benzothiazoleS-carboxylic acid esters shown in Fig. 9, with $\mathrm{O}$ was performed to synthesize 2-benzoxazole-S-carboxylic acid esters shown in Fig. 10.

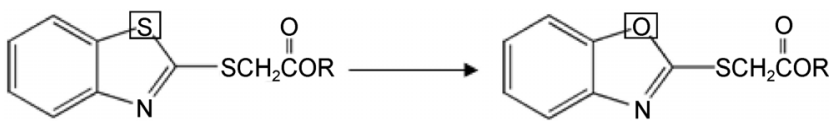

Fig. 8 Scheme 5.

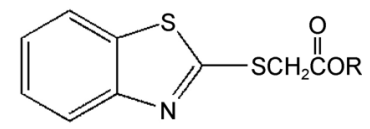

Fig. 9 The structural formula of the compound.

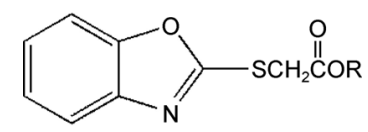

Fig. 10 The structural formula of the compound.

\subsubsection{Preparation of 2-benzothiazole-S-carboxylic acid esters and isosteres}

The synthesis route of 2-benzothiazole-S-carboxylic 
Table 1 The tribological test results of the corresponding lubricant with thiobenzothiazole compounds or isosteres.

\begin{tabular}{|c|c|c|c|c|c|c|c|c|c|c|c|c|c|}
\hline \multirow[b]{2}{*}{$\begin{array}{l}\text { Molecular } \\
\text { property }\end{array}$} & \multirow{2}{*}{$\begin{array}{l}\text { Additive } \\
\begin{array}{c}\text { Molecular structural } \\
\text { formula }\end{array}\end{array}$} & \multicolumn{2}{|c|}{$\begin{array}{c}\text { Anti-wear in } \\
\text { bis(2-ethylhexyl) } \\
\text { adipate }\end{array}$} & \multicolumn{2}{|c|}{$\begin{array}{l}\text { Friction-reduction in } \\
\text { bis(2-ethylhexyl) } \\
\text { adipate }\end{array}$} & \multicolumn{2}{|c|}{$\begin{array}{l}\text { Anti-wear in } \\
\text { triisodecyl trimellitate }\end{array}$} & \multicolumn{2}{|c|}{$\begin{array}{l}\text { Friction-reduction in } \\
\text { triisodecyl trimellitate }\end{array}$} & \multicolumn{2}{|c|}{$\begin{array}{l}\text { Anti-wear in } \\
\text { TMPTO }\end{array}$} & \multicolumn{2}{|c|}{$\begin{array}{l}\text { Friction-reduction } \\
\text { in TMPTO }\end{array}$} \\
\hline & & $\begin{array}{l}\text { Width of the } \\
\text { wear scar } \\
(\mathrm{mm})\end{array}$ & $\begin{array}{l}\text { Deviation } \\
\quad(\%)\end{array}$ & $\begin{array}{l}\text { Friction } \\
\text { coefficient }\end{array}$ & $\begin{array}{l}\text { Deviation } \\
\quad(\%)\end{array}$ & $\begin{array}{l}\text { Width of } \\
\text { the wear } \\
\text { scar }(\mathrm{mm})\end{array}$ & $\begin{array}{l}\text { Deviation } \\
\quad(\%)\end{array}$ & $\begin{array}{l}\text { Friction } \\
\text { coefficient }\end{array}$ & $\begin{array}{l}\text { Deviation } \\
(\%)\end{array}$ & $\begin{array}{l}\text { Width of } \\
\text { the wear } \\
\text { scar }(\mathrm{mm})\end{array}$ & $\begin{array}{l}\text { Deviation } \\
\quad(\%)\end{array}$ & $\begin{array}{l}\text { Friction } \\
\text { coefficient }\end{array}$ & $\begin{array}{l}\text { Deviation } \\
(\%)\end{array}$ \\
\hline Template & $\mathrm{n}-\mathrm{C}_{3} \mathrm{H}_{7} \mathrm{~S}$ & 0.801 & & 0.1212 & & 0.475 & & 0.1124 & & 0.855 & & 0.1149 & \\
\hline \multirow{2}{*}{ Isostere } & $n-C$ & 0.858 & 7.12 & 0.1239 & 2.23 & 0.618 & 30.11 & 0.1127 & 0.27 & 0.848 & -0.82 & 0.1169 & 1.74 \\
\hline & $\mathrm{n}-\mathrm{C}_{3} \mathrm{H}_{7} \mathrm{~S}$ & 0.675 & -15.73 & 0.1017 & -16.09 & 0.478 & 0.63 & 0.1017 & -9.52 & 0.763 & -10.76 & 0.1084 & -5.66 \\
\hline Template & $\mathrm{n}-\mathrm{C}_{4} \mathrm{H}_{9} \mathrm{~S}$ & 0.767 & & 0.1202 & & 0.515 & & 0.1104 & & 0.980 & & 0.1055 & \\
\hline \multirow{2}{*}{ Isostere } & $\mathrm{n}-\mathrm{C}_{4} \mathrm{H}_{3}$ & 0.840 & 9.52 & 0.1274 & 5.99 & 0.578 & 12.23 & 0.1022 & -7.43 & 0.875 & -10.71 & 0.1094 & 3.70 \\
\hline & $\mathrm{n}-\mathrm{C}_{4} \mathrm{H}_{9} \mathrm{~S}$ & 0.722 & -5.87 & 0.1084 & -9.82 & 0.512 & -0.58 & 0.1084 & -1.81 & 0.868 & -11.43 & 0.1150 & 9.00 \\
\hline Template & $\mathrm{n}-\mathrm{C}_{5} \mathrm{H}_{11} \mathrm{~S}$ & 0.822 & & 0.1229 & & 0.568 & & 0.1090 & & 0.845 & & 0.1150 & \\
\hline \multirow{2}{*}{ Isostere } & $\mathrm{n}-\mathrm{C}_{5} \mathrm{H}_{11} \mathrm{~S}-$ & 0.817 & -0.61 & 0.1178 & -4.15 & 0.645 & 13.56 & 0.1043 & -4.31 & 0.872 & 3.20 & 0.1114 & -3.13 \\
\hline & $\mathrm{n}-\mathrm{C}_{5} \mathrm{H}_{11} \mathrm{~S}$ & 0.760 & -7.54 & 0.1155 & -6.02 & 0.511 & -10.04 & 0.1161 & 6.51 & 0.953 & 12.78 & 0.1208 & 5.04 \\
\hline Template & $\mathrm{n}-\mathrm{C}_{6} \mathrm{H}_{13} \mathrm{~S}-$ & 0.713 & & 0.1160 & & 0.550 & & 0.1073 & & 0.945 & & 0.1122 & \\
\hline \multirow{2}{*}{ Isostere } & $\mathrm{n}-\mathrm{C}_{6} \mathrm{H}_{13} \mathrm{~S}-$ & 0.737 & 3.37 & 0.1126 & -2.93 & 0.623 & 13.27 & 0.1061 & -1.12 & 0.845 & -10.58 & 0.1110 & -1.07 \\
\hline & $\mathrm{n}-\mathrm{C}_{6} \mathrm{H}_{13} \mathrm{~S}$ & 0.828 & 16.13 & 0.1079 & -6.98 & 0.532 & -3.27 & 0.1079 & 0.56 & 0.917 & -2.96 & 0.1192 & 6.24 \\
\hline Template & $\mathrm{n}-\mathrm{C}_{7} \mathrm{H}_{15} \mathrm{~S}$ & 0.785 & & 0.1227 & & 0.515 & & 0.1074 & & 0.812 & & 0.1139 & \\
\hline \multirow{2}{*}{ Isostere } & $\mathrm{n}-\mathrm{C}_{7} \mathrm{H}_{15} \mathrm{~S}$ & 0.762 & -2.93 & 0.1188 & -3.18 & 0.543 & 5.44 & 0.1063 & -1.02 & 0.768 & -5.42 & 0.1007 & -11.59 \\
\hline & $\mathrm{n}-\mathrm{C}_{7} \mathrm{H}_{15} \mathrm{~S}-$ & 0.785 & 0 & 0.1116 & -9.05 & 0.603 & 17.09 & 0.1116 & 3.91 & 0.861 & 6.03 & 0.1149 & 0.88 \\
\hline Template & $\mathrm{n}-\mathrm{C}_{8} \mathrm{H}_{17} \mathrm{~S}-$ & 0.785 & & 0.1265 & & 0.743 & & 0.1163 & & 0.753 & & 0.1061 & \\
\hline \multirow{2}{*}{ Isostere } & $\mathrm{n}-\mathrm{C}_{8} \mathrm{H}_{17} \mathrm{~S}$ & 0.963 & 22.68 & 0.1300 & 2.77 & 0.585 & -21.27 & 0.1028 & -11.61 & 0.923 & 22.58 & 0.1138 & 7.26 \\
\hline & $\mathrm{n}-\mathrm{C}_{8} \mathrm{H}_{17} \mathrm{~S}-$ & 0.802 & 2.17 & 0.1104 & -12.73 & 0.503 & -32.30 & 0.1104 & -5.07 & 0.813 & 7.97 & 0.1179 & 11.12 \\
\hline
\end{tabular}

acid esters is referred to as Scheme 6 and is given by Fig. 11.

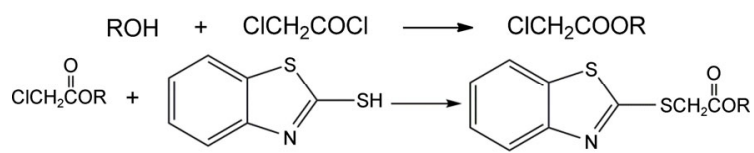

Fig. 11 Scheme 6.
Six isosteres were synthesized (Scheme 7 in Fig. 12), as shown in Table 2.

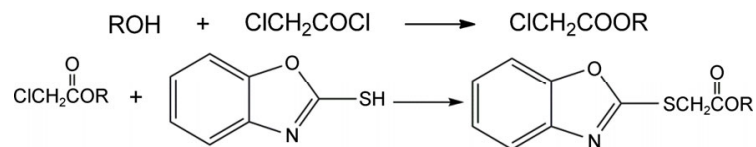

Fig. 12 Scheme 7. 
Table 2 The tribological test results of the corresponding lubricant with 2-benzothiazole-S-carboxylic acid esters or isosteres.

\begin{tabular}{|c|c|c|c|c|c|c|c|c|c|c|c|c|c|}
\hline \multirow[b]{2}{*}{$\begin{array}{l}\text { Molecular } \\
\text { property }\end{array}$} & \multirow{2}{*}{$\begin{array}{c}\text { Additive } \\
\begin{array}{c}\text { Molecular structural } \\
\text { formula }\end{array}\end{array}$} & \multicolumn{2}{|c|}{$\begin{array}{c}\text { Anti-wear in } \\
\text { bis(2-ethylhexyl) } \\
\text { adipate }\end{array}$} & \multicolumn{2}{|c|}{$\begin{array}{c}\text { Friction-reduction } \\
\text { in bis(2-ethylhexyl) } \\
\text { adipate }\end{array}$} & \multicolumn{2}{|c|}{$\begin{array}{l}\text { Anti-wear in } \\
\text { triisodecyl } \\
\text { trimellitate }\end{array}$} & \multicolumn{2}{|c|}{$\begin{array}{c}\text { Friction-reduction in } \\
\text { triisodecyl } \\
\text { trimellitate }\end{array}$} & \multicolumn{2}{|c|}{$\begin{array}{l}\text { Anti-wear in } \\
\text { TMPTO }\end{array}$} & \multicolumn{2}{|c|}{$\begin{array}{l}\text { Friction-reduction } \\
\text { in TMPTO }\end{array}$} \\
\hline & & $\begin{array}{l}\text { Width of the } \\
\text { wear scar } \\
(\mathrm{mm})\end{array}$ & $\begin{array}{c}\text { Deviation } \\
(\%)\end{array}$ & $\begin{array}{l}\text { Friction } \\
\text { coefficient }\end{array}$ & $\begin{array}{c}\text { Deviation } \\
(\%)\end{array}$ & $\begin{array}{l}\text { Width of } \\
\text { the wear } \\
\text { scar }(\mathrm{mm})\end{array}$ & $\begin{array}{l}\text { Deviation } \\
\quad(\%)\end{array}$ & $\begin{array}{l}\text { Friction } \\
\text { coefficient }\end{array}$ & $\begin{array}{l}\text { Deviation } \\
\quad(\%)\end{array}$ & $\begin{array}{l}\text { Width of } \\
\text { the wear } \\
\text { scar }(\mathrm{mm})\end{array}$ & $\begin{array}{l}\text { Deviation } \\
\quad(\%)\end{array}$ & $\begin{array}{l}\text { Friction } \\
\text { coefficient }\end{array}$ & $\begin{array}{c}\text { Deviation } \\
(\%)\end{array}$ \\
\hline Template & $\mathrm{n}-\mathrm{C}_{4} \mathrm{H}_{9} \mathrm{OOCH}_{2}$ & 0.832 & & 0.1230 & & 0.425 & & 0.0981 & & 0.792 & & 0.1098 & \\
\hline Isostere & $\mathrm{n}-\mathrm{C}_{4} \mathrm{H}_{9} \mathrm{OOCH} \mathrm{CS}_{2}$ & 0.972 & 16.83 & 0.1333 & 8.37 & 0.472 & 11.06 & 0.0946 & -3.57 & 0.862 & 8.84 & 0.1106 & 0.73 \\
\hline Template & $\mathrm{n}-\mathrm{C}_{5} \mathrm{H}_{11} \mathrm{OOCH} \mathrm{CS}_{2} \mathrm{CS}$ & 0.777 & & 0.1205 & & 0.572 & & 0.1008 & & 0.802 & & 0.1080 & \\
\hline Isostere & $\mathrm{n}-\mathrm{C}_{5} \mathrm{H}_{11} \mathrm{OOCH}$ & 0.828 & 6.56 & 0.1205 & 0 & 0.475 & -16.96 & 0.1057 & 4.86 & 0.952 & 18.70 & 0.1145 & 6.02 \\
\hline Template & $\mathrm{n}-\mathrm{C}_{6} \mathrm{H}_{13} \mathrm{OOCH}_{2} \mathrm{CS}$ & 0.798 & & 0.1186 & & 0.517 & & 0.1032 & & 0.865 & & 0.1114 & \\
\hline Isostere & $\mathrm{n}-\mathrm{C}_{6} \mathrm{H}_{13} \mathrm{OOCH} \mathrm{H}_{2} \mathrm{CS}$ & 0.808 & 1.25 & 0.1193 & 0.59 & 0.470 & -9.09 & 0.0994 & -3.68 & 0.957 & 10.64 & 0.1147 & 2.96 \\
\hline Template & $\mathrm{n}-\mathrm{C}_{7} \mathrm{H}_{15} \mathrm{OOCH} \mathrm{H}_{2} \mathrm{CS}$ & 0.980 & & 0.1259 & & 0.495 & & 0.1026 & & 0.993 & & 0.1160 & \\
\hline Isostere & $\mathrm{n}-\mathrm{C}_{7} \mathrm{H}_{15} \mathrm{OOCH}_{2} \mathrm{CS}$ & 0.825 & -15.82 & 0.1203 & -4.45 & 0.598 & 20.81 & 0.1076 & 4.87 & 0.947 & -4.63 & 0.1158 & -0.17 \\
\hline Template & $\mathrm{n}-\mathrm{C}_{8} \mathrm{H}_{17} \mathrm{OOCH}$ & 0.830 & & 0.1170 & & 0.483 & & 0.1049 & & 0.803 & & 0.1068 & \\
\hline Isostere & $\mathrm{n}-\mathrm{C}_{8} \mathrm{H}_{1}-\mathrm{OOCH}_{2} \mathrm{C}$ & 0.915 & 10.24 & 0.1260 & 7.69 & 0.495 & 2.48 & 0.1040 & -0.86 & 0.812 & 1.12 & 0.1086 & 1.69 \\
\hline Template & $\mathrm{n}-\mathrm{C}_{9} \mathrm{H}_{19} \mathrm{OOCH}{ }_{2} \mathrm{CS}$ & 0.858 & & 0.1226 & & 0.462 & & 0.1024 & & 0.888 & & 0.1134 & \\
\hline Isostere & $\mathrm{n}-\mathrm{C}_{9} \mathrm{H}_{19} \mathrm{OOCH} \mathrm{CS}_{2}-$ & 0.868 & 1.17 & 0.1254 & 2.28 & 0.568 & 22.94 & 0.1033 & 0.88 & 0.832 & -6.31 & 0.1065 & -6.08 \\
\hline
\end{tabular}

\subsection{Tribology tests}

It is necessary to employ the synthetic ester as a lubricant base oil under extremely harsh conditions and to study the new lubricant additives for the synthetic ester. Therefore, trimethylolpropane trioleate (TMPTO), triisodecyl trimellitate, and bis(2-ethylhexyl) adipate were used as base oils. The molecular structural formulas of the base oils are shown in Fig. 13. Lubricants were formed when $1 \mathrm{wt} . \%$ of a template molecule or an isostere were separately dissolved in a base oil.

A series of ball-disc contact friction tests were carried out using a microtribometer (UMT-3, CETR) to investigate the tribological characteristics of steel/steel rubbing pairs immersed in the corresponding lubricant. The experimental conditions were as follows: (1) a steel ball (52100, $4.45 \mathrm{~mm}$ in diameter) and the back of a NSK 51103 thrust ball bearing (steel 52100) as the sample; (2) a relatively low rotational velocity,

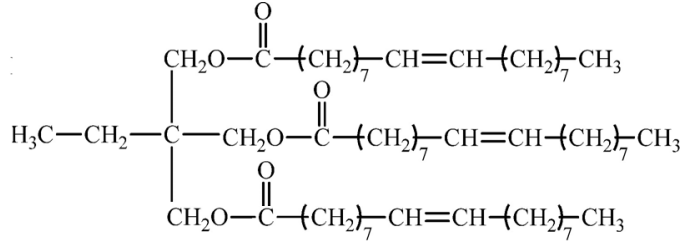

(a) TMPTO<smiles>CC(C)CCOC(=O)c1ccc(C(=O)OCCC(C)C)c(C(=O)OCCC(C)C)c1</smiles>

(b) Triisodecyl trimellitate<smiles>CCCCC(CC)COC(=O)CCC(C)(C)C(=O)OCC(CC)c1ccccc1</smiles>

(c) Bis(2-ethylhexyl) adipate

Fig. 13 Molecular structural formula of base oil. 
$v=60.18 \mathrm{~mm} / \mathrm{s}$; (3) a normal load, $L=98 \mathrm{~N}$; and (4) time, $t=60 \mathrm{~min}[4,6]$. The diameter of the wear scale on the steel ball was measured using an optical microscope equipped with a scale. The friction coefficient was automatically recorded, and the average value of the friction coefficient was calculated by the system. Each of the lubricants was tested three times. The "diameter of wear scar" or the "friction coefficient" is the average value of the three tests.

In order to build a universal data set for future work, the tribological test method and conditions were kept in accordance with the previous tests mentioned in the published papers $[16,18,20]$.

\subsection{QSTR models with CoMFA and CoMSIA}

\subsubsection{CoMFA-QSTR and CoMSIA-QSTR lubricant additive models for anti-wear}

Data for each anti-wear set of 18 organic compounds (lubricant additives, a column in Table 1) in the different base oils used along with their anti-wear data were included in the COMFA or CoMSIA-QSTR models, respectively. To determine the anti-wear capability of each molecule, the wear scar widths were related through simple mathematical manipulation.

$$
\mathrm{WS}_{(98 \mathrm{~N})}=\frac{w \cdot \mathrm{MW} \cdot \text { Conc }}{w_{0}}
$$

In Eq. (1), WS represents the anti-wear scar scale, $w$ is the measured size of the wear scar width in additive-containing lubricant, $w_{0}$ is the measured size of the wear scar width in pure base oil, MW is the molecular weight of the compound, and Conc is the percent concentration of the additive.

A total of 18 molecules were considered for this study, and CoMFA or CoMSIA models were developed for both the training $(n=15)$ and the test set molecules $(n=3)$. The test set was used to validate the developed models. The model was carried out in steric and electrostatic fields. The relationship between the structural parameters and the WS values was quantified by a partial least squares (PLS) algorithm. The regression coefficient $R^{2}$, the cross-validation coefficient $R_{(\mathrm{LOO})}^{2}$ and $q^{2}$ were also calculated [3-6, 22]. $q^{2}$ was computed according to the formula:

$$
q^{2}=1-\frac{\sum_{i}\left(\operatorname{pred}_{i}-\mathrm{obs}_{i}\right)^{2}}{\sum_{i}\left(\mathrm{obs}_{i}-\overline{\mathrm{obs}}\right)^{2}}
$$

\subsubsection{CoMFA-QSTR and COMSIA-QSTR lubricant additive models for friction-reduction}

CoMFA and CoMSIA analysis for friction-reduction were carried out on each friction-reduction set of 18 organic compounds (lubricant additives, a column in Table 1) in the different base oils, respectively.

To determine the friction-reduction performance of each molecule, the friction coefficients were related through simple mathematical manipulation.

$$
\mathrm{FS}_{(98 \mathrm{~N})}=\frac{f \cdot \mathrm{MW} \cdot \text { Conc }}{f_{0}}
$$

In Eq. (3), FS represents the friction-reduction scale, $f$ is the friction coefficient in the modified lubricant, $f_{0}$ is the friction coefficient in pure base oil, MW is the molecular weight of the compound, and Conc is the percent concentration of the additive.

The detailed steps of building the model were similar to the COMFA-QSTR and CoMSIA-QSTR antiwear models.

\section{Results and discussion}

\subsection{Similarity assessment of isosteres}

The tribology test results of the lubricants formed using the template molecules and their isosteres are shown in Tables 1 and 2 and also in Figs. 14-25. Changes in

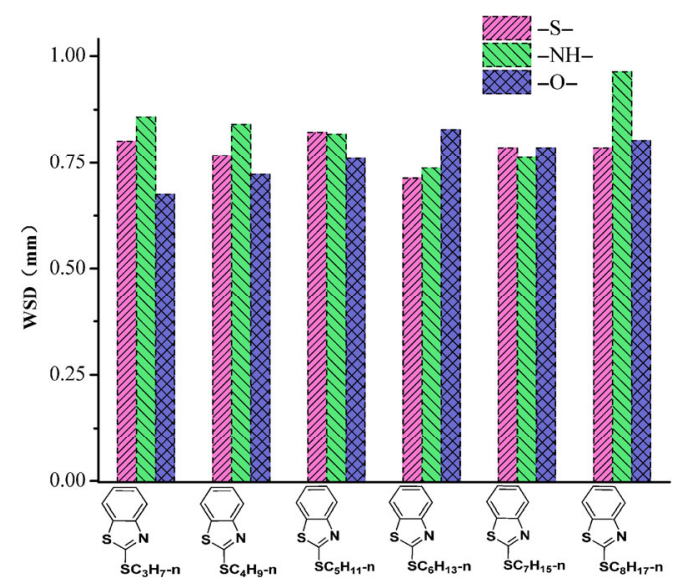

Fig. 14 The wear scar width of each steel ball when lubricating with thiobenzothiazole compounds and their isosteres in bis(2ethylhexyl) adipate. 


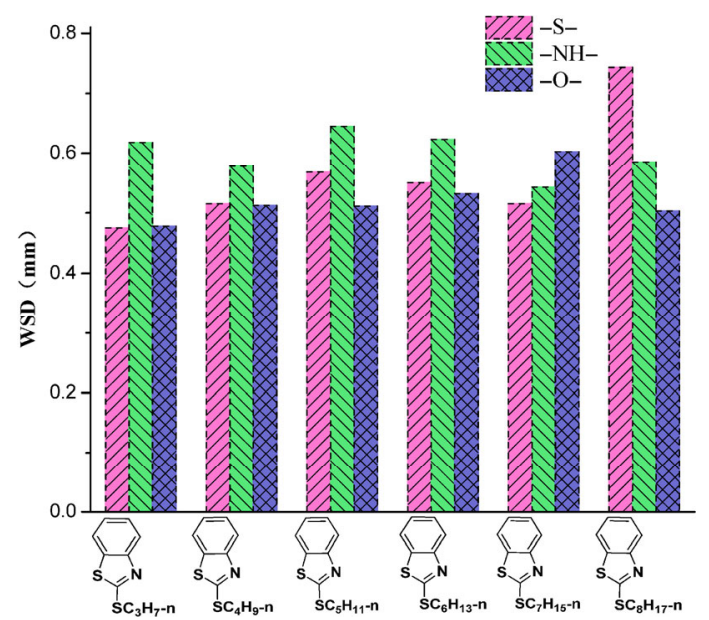

Fig. 15 The wear scar width of each steel ball when lubricating with thiobenzothiazole compounds and their isosteres in triisodecyl trimellitate.

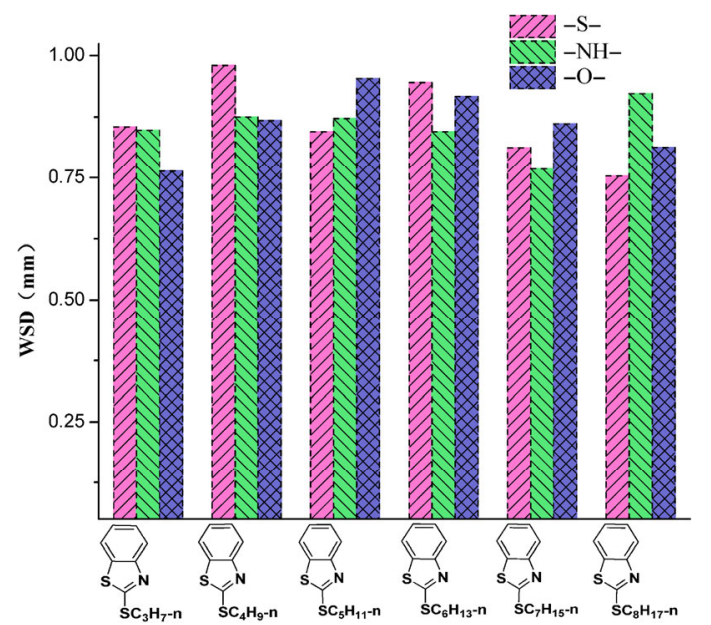

Fig. 16 The wear scar width of each steel ball when lubricating with thiobenzothiazole compounds and their isosteres in TMPTO.

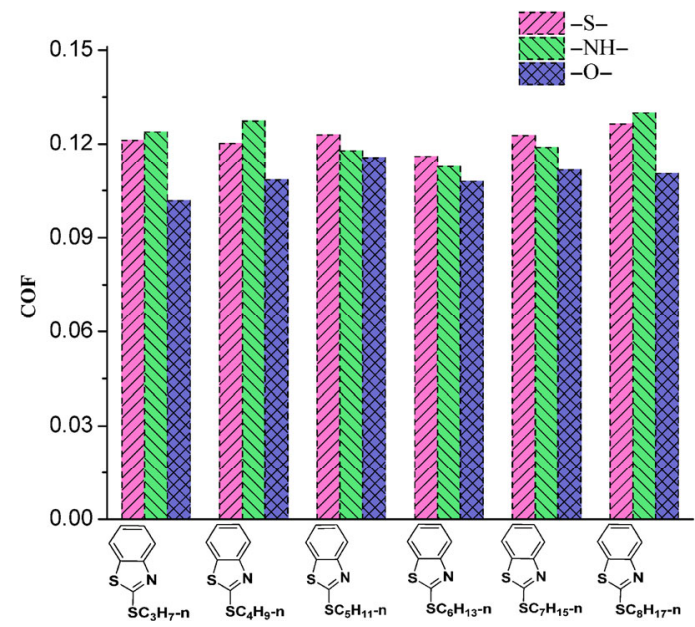

Fig. 17 The friction coefficient when lubricating with thiobenzothiazole compounds and their isosteres in bis(2-ethylhexyl) adipate.

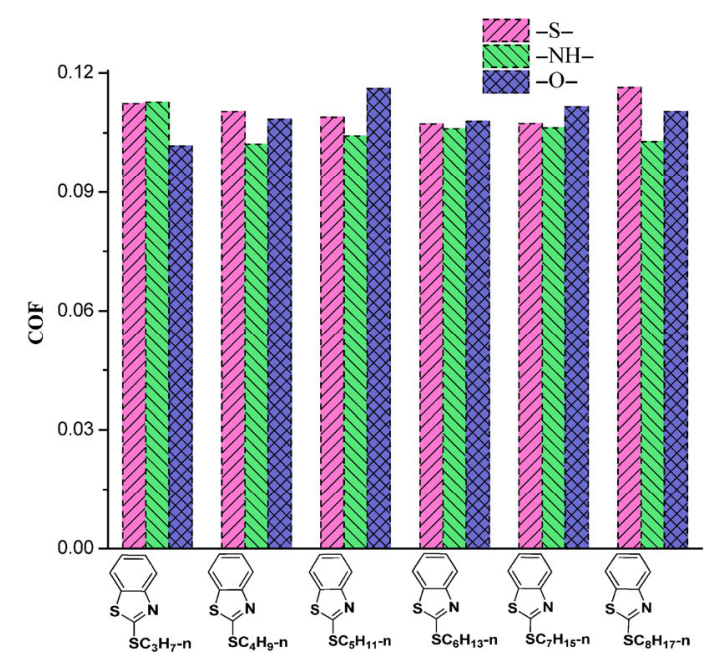

Fig. 18 The friction coefficient when lubricating with thiobenzothiazole compounds and their isosteres in triisodecyl trimellitate.

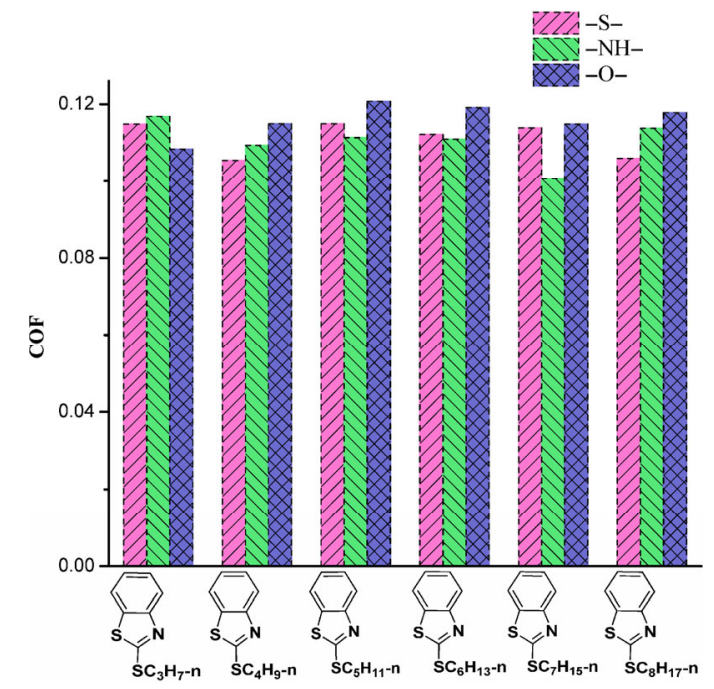

Fig. 19 The friction coefficient when lubricating with thiobenzothiazole compounds and their isosteres in TMPTO.

the tribological properties between the individual isosteres and the template molecule were calculated. A deviation refers to the difference between the actual data and the target values, and is given by

$$
\text { Deviation }=\frac{X-A}{A}
$$

where $A$ is the target value, and $X$ is actual data.

\subsection{Similarity assessment of isosteres based on thiobenzothiazole}

There were six template molecules and twelve isosteres. Changes in the tribology between individual isosteres and their template molecules based on 


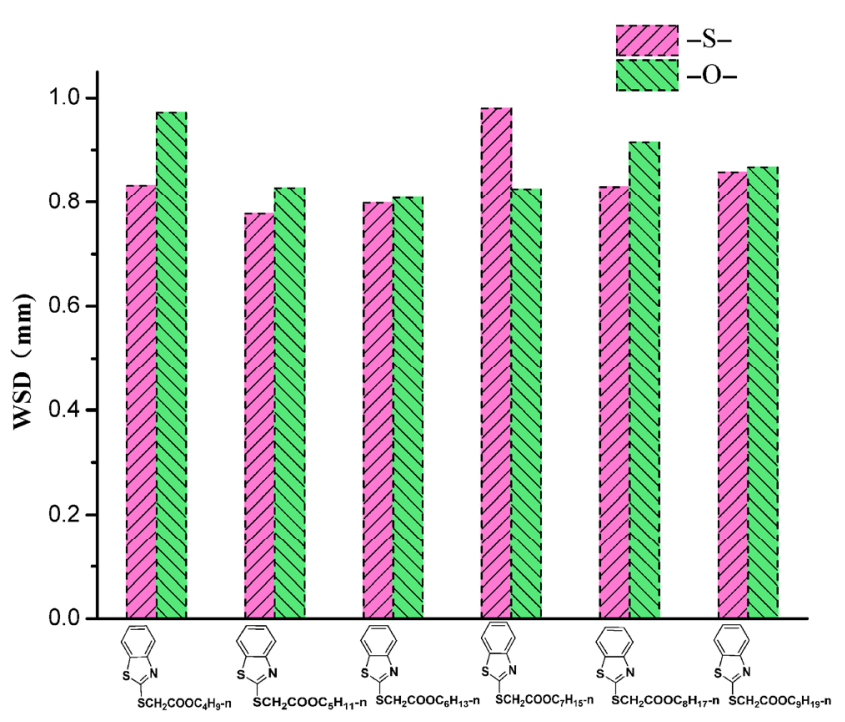

Fig. 20 The wear scar width of each steel ball when lubricating with 2-benzothiazole-S-carboxylic acid esters and their isosteres in bis(2-ethylhexyl) adipate.

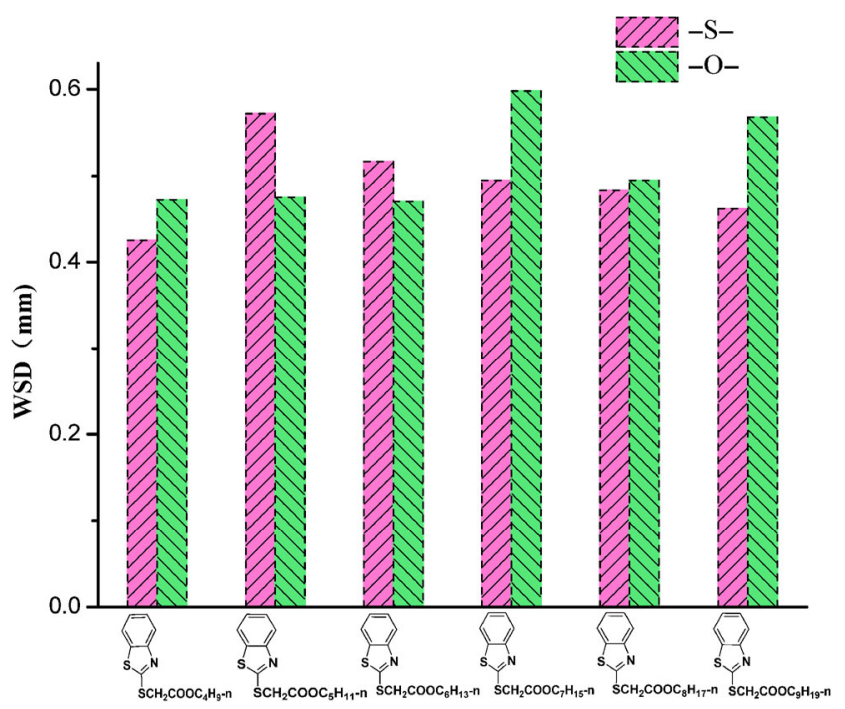

Fig. 21 The wear scar width of each steel ball when lubricating with 2-benzothiazole-S-carboxylic acid esters and their isosteres in triisodecyl trimellitate.

thiobenzothiazole compounds are shown in Table 3.

\subsubsection{Anti-wear performance}

Anti-wear performance of the lubricants formed with thiobenzothiazole compounds and their isosteres are shown in Table 1 and Figs. 14-16. Ignoring the specific changes in the base oils and the differences in molecular structure, there were 36 groups of isosteres for the anti-wear experiments. The results of the similarity assessment concerning isostere anti-wear

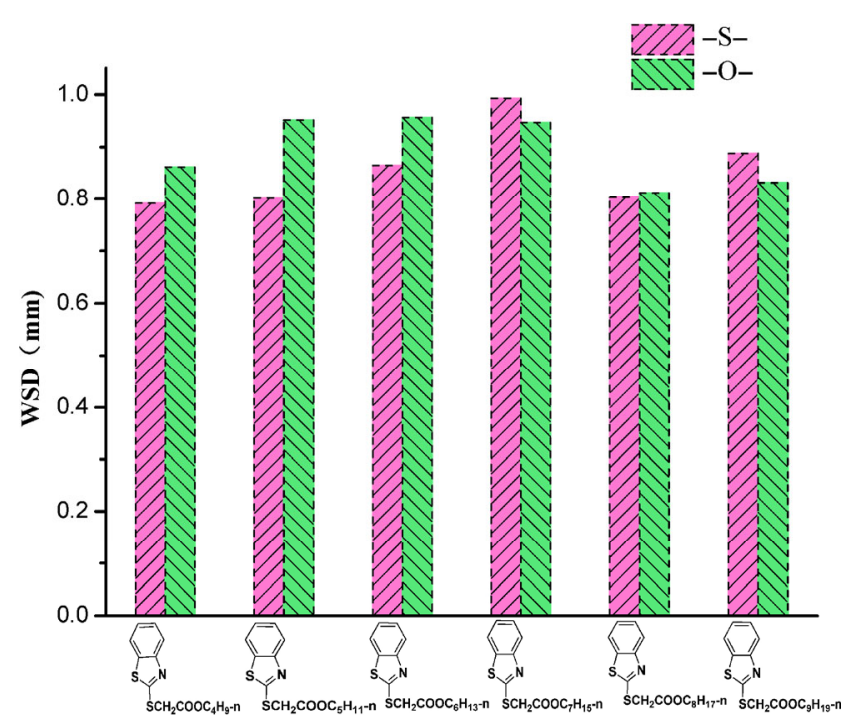

Fig. 22 The wear scar width of each steel ball when lubricating with 2-benzothiazole-S-carboxylic acid esters and their isosteres in TMPTO.

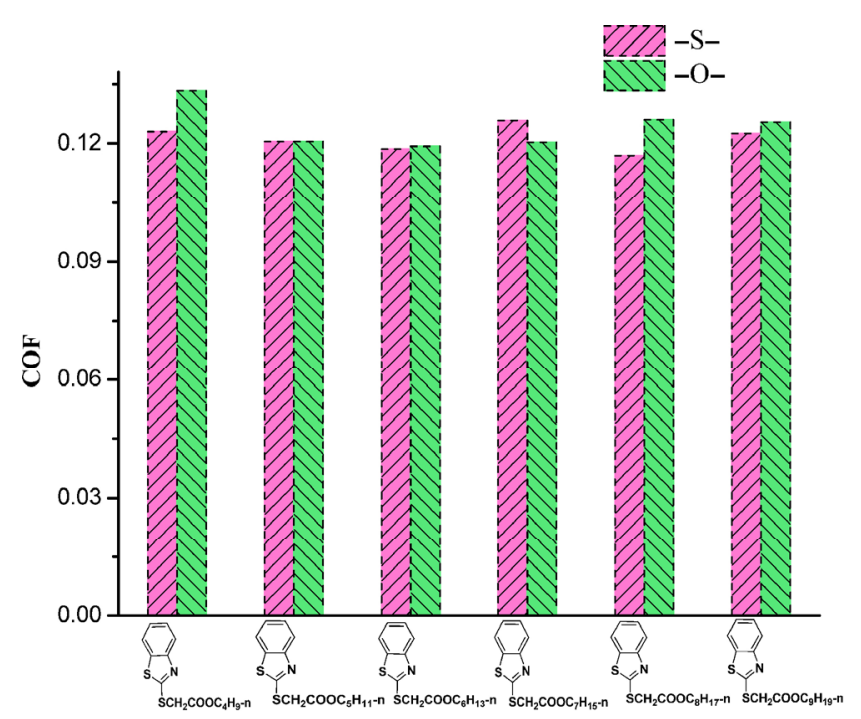

Fig. 23 The friction coefficient when lubricating with 2benzothiazole-S-carboxylic acid esters and their isosteres in bis(2-ethylhexyl) adipate.

performance revealed that: (1) within a $\pm 1 \%$ deviation, there are five compounds (13.89\% of the isosteres); (2) within a $\pm 5 \%$ deviation, there are 11 compounds (30.56\% of the isosteres); (3) within a $\pm 10 \%$ deviation, there are 19 compounds (52.78\% of the isosteres); (4) there are eight compounds with absolute values of deviation greater than $15 \%$ (22.22\% of the isosteres); finally (5) there are 18 compounds $(50.00 \%$ of the isosteres), with an anti-wear performance that are consistent with or better than that of the template molecules. 
Table 3 Similarity assessment of isosteres based on thiobenzothiazole compounds.

\begin{tabular}{|c|c|c|c|c|c|c|}
\hline \multirow[t]{2}{*}{ Deviation $(\%)$} & \multicolumn{2}{|c|}{ Anti-wear } & \multicolumn{2}{|c|}{ Friction-reduction } & \multicolumn{2}{|c|}{ Anti-wear or friction-reduction } \\
\hline & $\begin{array}{c}\text { Number of } \\
\text { isosteres }\end{array}$ & $\begin{array}{l}\text { Proportion } \\
\quad(\%)\end{array}$ & $\begin{array}{c}\text { Number of } \\
\text { isosteres }\end{array}$ & $\begin{array}{l}\text { Proportion } \\
\quad(\%)\end{array}$ & $\begin{array}{c}\text { Number of } \\
\text { isosteres }\end{array}$ & $\begin{array}{l}\text { Proportion } \\
(\%)\end{array}$ \\
\hline \pm 1 & 5 & 13.89 & 3 & 8.33 & 8 & 11.11 \\
\hline \pm 5 & 11 & 30.56 & 17 & 47.22 & 28 & 38.89 \\
\hline \pm 10 & 19 & 52.78 & 31 & 86.11 & 50 & 69.44 \\
\hline \pm 15 & 28 & 77.78 & 35 & 97.22 & 63 & 87.50 \\
\hline$>15$ (the absolute value of deviation) & 8 & 22.22 & 1 & 2.78 & 9 & 12.50 \\
\hline $\begin{array}{l}\text { Isosteres (property consistent with or better } \\
\text { than the templates) }\end{array}$ & 18 & 50.00 & 21 & 58.33 & 39 & 54.17 \\
\hline
\end{tabular}

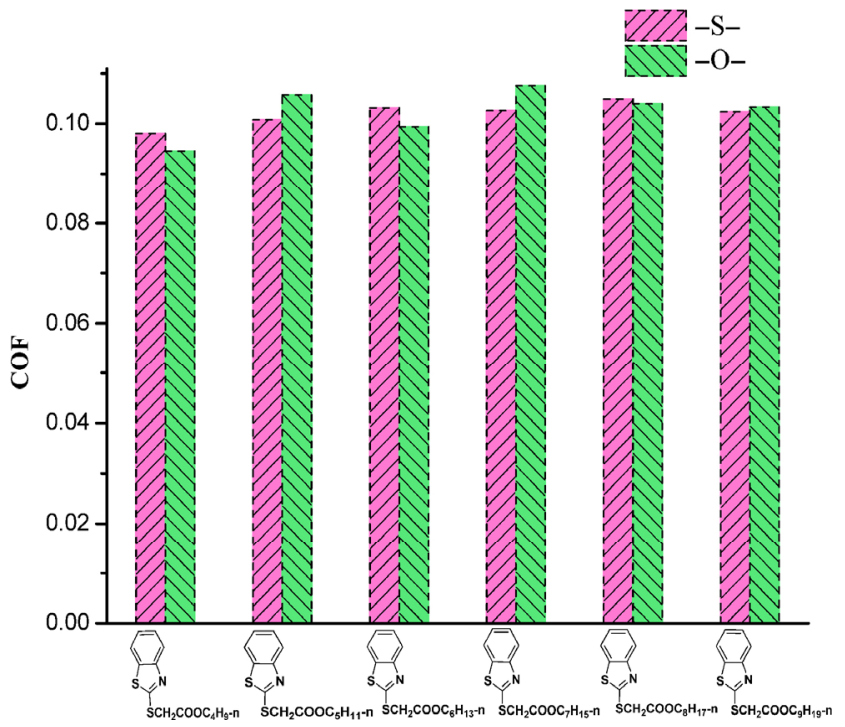

Fig. 24 The friction coefficient when lubricating with 2benzothiazole-S-carboxylic acid esters and their isosteres in triisodecyl trimellitate.

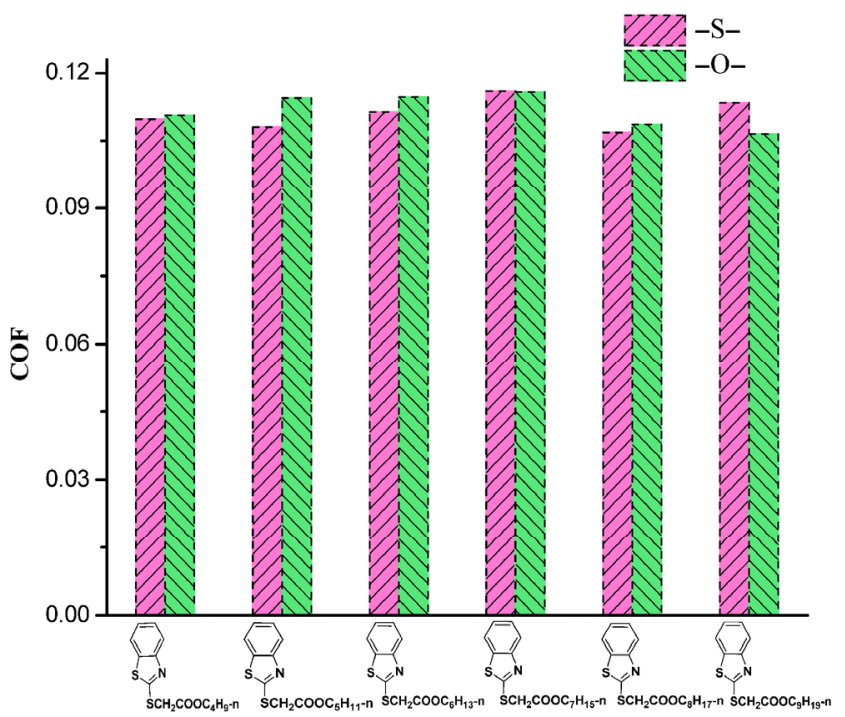

Fig. 25 The friction coefficient when lubricating with 2benzothiazole-S-carboxylic acid esters and their isosteres in TMPTO.
Relative to the corresponding template molecule, three special isosteres appeared among the eight compounds with absolute values of deviation greater than $15 \%$ and with significantly improved anti-wear characteristics, as shown in Figs. 26(a)-(c).

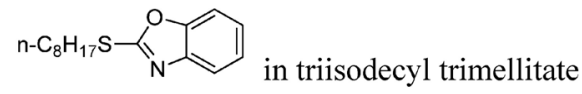

(a) $32.30 \%$ improvement in anti-wear

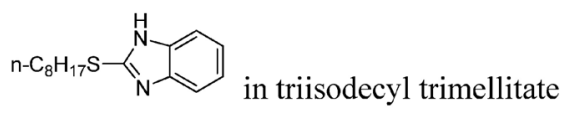

(b) $21.27 \%$ improvement in anti-wear

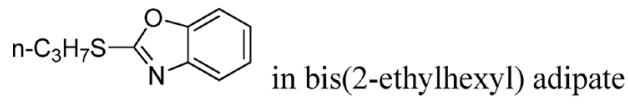

(c) $15.73 \%$ improvement in anti-wear

Fig. 26 The structural formula of the compound.

To some extent, it can be said that the three isosteres were revealed via molecular modification. In contrast, among these eight compounds, some exhibited adverse anti-wear effects, as shown in Figs. 27(a)-(c).

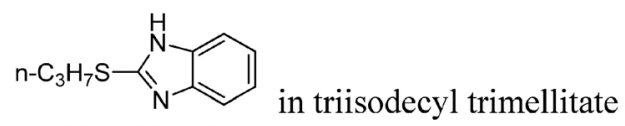

(a) $30.11 \%$ reduction in anti-wear effect

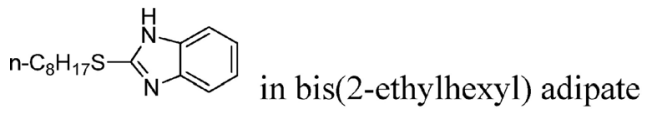

(b) $22.68 \%$ reduction in anti-wear effect

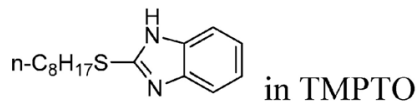

(c) $22.58 \%$ reduction in anti-wear effect

Fig. 27 The structural formula of the compound. 


\subsubsection{Friction-reduction performance}

Friction-reduction performance of the lubricants formed with thiobenzothiazole compounds and their isosteres are shown in Table 1 and in Figs. 17-19. Ignoring the specific changes in the base oils and the differences in molecular structure, there were 36 groups of isosteres for the friction-reduction experiments. The results of the similarity assessment in regards to isostere friction-reduction performance indicate that: (1) within a $\pm 1 \%$ deviation, there are three compounds ( $8.33 \%$ of the isosteres); (2) within a $\pm 5 \%$ deviation, there are 17 compounds (47.22\% of the isosteres); (3) within a $\pm 10 \%$ deviation, there are 31 compounds (86.11\% of the isosteres); (4) there is only one compound with an absolute value of deviation greater than $15 \%$ (2.78\% of the isosteres); finally (5) there are 21 compounds (58.33\% of the isosteres) with a friction-reduction performance that are consistent with or better than that of the template molecules.

Relative to the corresponding template molecule, some isosteres had improved friction-reduction effects, as shown in Figs. 28(a)-(d).

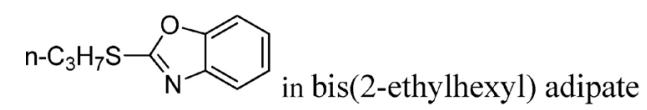

(a) $16.09 \%$ improvement in friction reduction

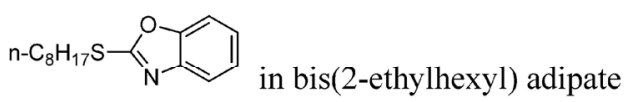

(b) $12.73 \%$ improvement in friction reduction

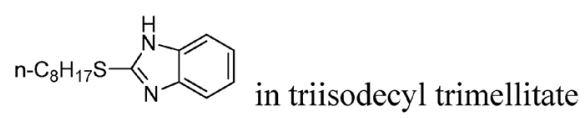

(c) $11.61 \%$ improvement in friction reduction

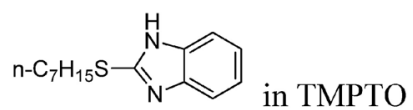

(d) $11.59 \%$ improvement in friction reduction

Fig. 28 The structural formula of the compound.

In contrast, the friction-reduction performance of the Fig. 29 isostere in TMPTO decreased by $11.12 \%$ relative to the corresponding template molecule in the same base oil.

Except for the Fig. 29 isostere, isosteres with absolute values of deviation greater than $10 \%$ exhibited much better friction-reduction than that of the template molecule in the corresponding base oil.

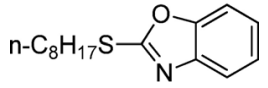

Fig. 29 The structural formula of the compound.

\subsubsection{Tribological performance}

Tribological performance of the lubricants formed with thiobenzothiazole compounds and their isosteres are shown in Table 1 and in Figs. 14-19. Ignoring the specific changes in the base oils, the differences in molecular structure, and friction or wear properties, there were 72 groups of isosteres in the tribology experiments. For the 72 groups of isosteres (ignoring the specific changes in the base oils, the differences in molecular structure, and without distinguishing specific tribological properties), in the similarity assessment of the tribological performance, the results indicate that: (1) within a $\pm 1 \%$ deviation, there are eight groups (11.11\% of the experiments); (2) within a $\pm 5 \%$ deviation, there are 28 groups $(38.89 \%$ of the experiments); (3) within a $\pm 10 \%$ deviation, there are 50 groups $(69.44 \%$ of the experiments); (4) there are nine groups with the absolute values of deviation greater than $15 \%$ ( $12.50 \%$ of the experiments); and (5) there are 39 experiment groups $(54.17 \%$ of the experiments) with a friction-reduction or anti-wear performance that are consistent with or better than that of the template molecules.

In regards to both friction-reduction and anti-wear performance of the 36 isosteres, there are 12 isosteres (33.33\% of all the isosteres) that exhibit consistent or better tribological performance than those of the template molecules.

Relative to the template molecule, both the frictionreduction and anti-wear performances of the isosteres significantly improved as shown in Figs. 30(a)-(e).

\subsubsection{The best isosteres for the different lubricant base oils}

In fact, there is no regularity in tribological performance; isosterism is employed to design new lubricant additives, and the tribo-ability can be increased, weakened, or yield an adverse effect. The best isosteres were chosen for the different lubricant base oils.

In bis(2-ethylhexyl) adipate, the Fig. 31 isostere is the best isostere additive. In tests, the width of the wear scar was $0.675 \mathrm{~mm}$ and the friction coefficient was 0.1017. In triisodecyl trimellitate, the same isostere 


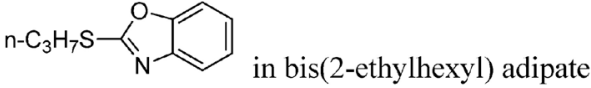

(a) $15.73 \%$ improved anti-wear effect and $16.09 \%$ improved friction-reduction effect

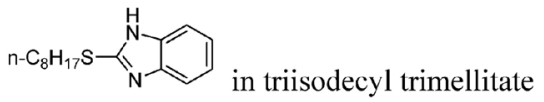

(b) $21.27 \%$ improved anti-wear effect and $11.61 \%$ improved friction-reduction effect

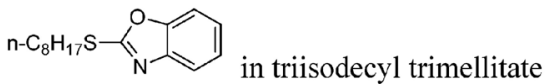

(c) $32.30 \%$ improved anti-wear effect and $5.07 \%$ improved friction-reduction effect

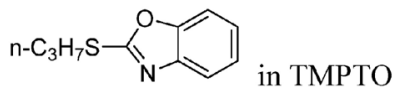

(d) $10.76 \%$ improved anti-wear effect and $5.66 \%$ improved friction-reduction effect

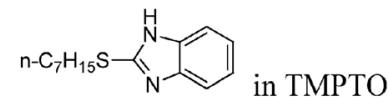

(e) $5.42 \%$ improved anti-wear effect and $11.59 \%$ improved friction-reduction effect

Fig. 30 The structural formula of the compound.

in Fig. 31 was found to be the best one. The results showed that the width of the wear scale was $0.478 \mathrm{~mm}$ and that the friction coefficient was 0.1017 .

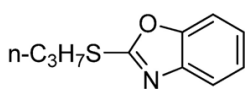

Fig. 31 The structural formula of the compound.

In TMPTO, the Figs. 31 and 32 isosteres both exhibited good tribological performances. With the former, the width of the wear scar was $0.763 \mathrm{~mm}$ and the friction coefficient was 0.1084 . With the latter, the width of the wear scar was $0.768 \mathrm{~mm}$ and the friction coefficient was 0.1007 .

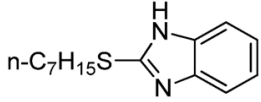

Fig. 32 The structural formula of the compound.

\subsection{Similarity assessment of isosteres based on 2-benzothiazole-S-carboxylic acid esters}

There were six template molecules and six isosteres. The deviations in tribological properties between the isosteres and the template molecules are shown in Table 4 .

\subsubsection{Anti-wear performance}

Anti-wear performance of the lubricants formed with 2-benzothiazole-S-carboxylic acid esters and their isosteres are shown in Table 2 and Figs. 20-22. Ignoring the specific changes in the base oils and the differences in molecular structure, there were 18 groups of isosteres for the antiwear experiment.

The results of the similarity assessment in regards to isostere anti-wear performance showed that: (1) within a $\pm 1 \%$ deviation, there is no compound ( $0 \%$ of the isosteres); (2) within a $\pm 5 \%$ deviation, there are five compounds ( $27.78 \%$ of the isosteres); (3) within a $\pm 10 \%$ deviation, there are nine compounds $(50.00 \%$ of the isosteres); (4) there are six compounds with absolute values of deviation greater than $15 \%$ (33.33\% of the isosteres); finally (5) there are 5 compounds $(27.78 \%$ of the isosteres) with an anti-wear performance that was consistent with or better than that of the template molecules.

Relative to the corresponding template molecule, some special isosteres appeared among the six compounds with absolute values of deviation greater than $15 \%$ and with significantly changed anti-wear

Table 4 Similarity assessment of isosteres based on 2-benzothiazole-S-carboxylic acid esters.

\begin{tabular}{|c|c|c|c|c|c|c|}
\hline \multirow[b]{2}{*}{ Deviation (\%) } & \multicolumn{2}{|c|}{ Anti-wear } & \multicolumn{2}{|c|}{ Friction-reduction } & \multicolumn{2}{|c|}{ Anti-wear or friction-reduction } \\
\hline & $\begin{array}{l}\text { Number of } \\
\text { isosteres }\end{array}$ & $\begin{array}{l}\text { Proportion } \\
(\%)\end{array}$ & $\begin{array}{l}\text { Number of } \\
\text { isosteres }\end{array}$ & $\begin{array}{l}\text { Proportion } \\
\quad(\%)\end{array}$ & $\begin{array}{l}\text { Number of } \\
\text { isosteres }\end{array}$ & $\begin{array}{c}\text { Proportion } \\
(\%)\end{array}$ \\
\hline \pm 1 & 0 & 0 & 6 & 33.33 & 6 & 16.67 \\
\hline \pm 5 & 5 & 27.78 & 14 & 77.78 & 19 & 52.78 \\
\hline \pm 10 & 9 & 50.00 & 18 & 100.00 & 27 & 75.00 \\
\hline \pm 15 & 12 & 66.67 & 18 & 100.00 & 30 & 83.33 \\
\hline$>15$ (the absolute value of deviation) & 6 & 33.33 & 0 & 0 & 6 & 16.67 \\
\hline $\begin{array}{l}\text { Isosteres (property consistent with or better } \\
\text { than the templates) }\end{array}$ & 5 & 27.78 & 7 & 38.89 & 12 & 33.33 \\
\hline
\end{tabular}


characteristics. These are shown in Figs. 33(a)-(e).

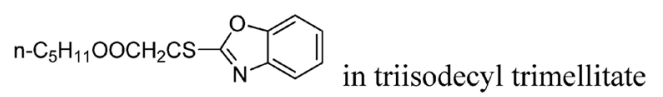

(a) 16.96\% improvement in anti-wear effect

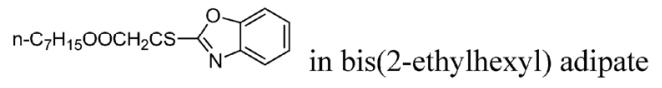

(b) $15.82 \%$ improvement in anti-wear effect

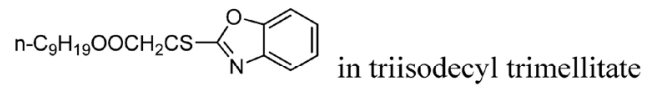

(c) $22.94 \%$ reduction in anti-wear effect

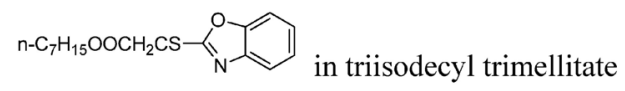

(d) $20.81 \%$ reduction in anti-wear effect

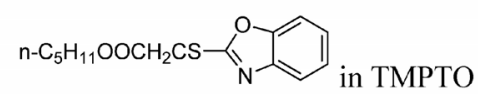

(e) $18.70 \%$ reduction in anti-wear effect

Fig. 33 The structural formula of the compound.

\subsubsection{Friction-reduction performance}

Friction-reduction performance of the lubricants formed with 2-benzothiazole-S-carboxylic acid esters and their isosteres are shown in Table 2 and Figs. 23-25. Ignoring the specific changes in the base oils, and the differences in molecular structure, there were 18 groups of isosteres for the friction-reduction experiments. The results of the similarity assessment in regards to isostere friction-reduction performance indicate that: (1) within a $\pm 1 \%$ deviation, there are six compounds (33.33\% of the isosteres); (2) within a $\pm 5 \%$ deviation, there are 14 compounds (77.78\% of the isosteres); (3) within a $\pm 10 \%$ deviation, there are 18 compounds (100\% of the isosteres); (4) there is no compound with an absolute value of deviation greater than $15 \%(0 \%$ of the isosteres); finally (5) there are seven compounds (38.89\% of the isosteres) with a friction-reduction performance that was consistent with or better than that of the template molecules.

Relative to the corresponding template molecule, some isosteres had distinguishable changes in frictionreduction effects, as shown in Figs. 34(a)-(c).

\subsubsection{Tribological performance}

Tribological performance of the lubricants formed with 2-benzothiazole-S-carboxylic acid esters and their isosteres are shown in Table 2 and Figs. 20-25. Ignoring the specific changes in the base oils, the

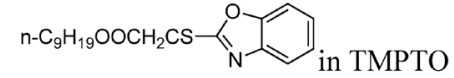

(a) $6.08 \%$ improvement in friction-reduction effect

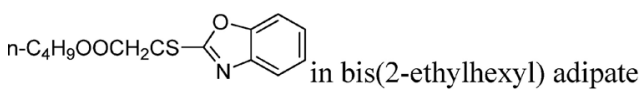

(b) $8.37 \%$ reduction in friction-reduction effect

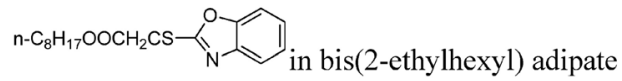

(c) $7.69 \%$ reduction in friction-reduction effect

Fig. 34 The structural formula of the compound.

differences in molecular structures, and the friction or wear properties, there were 36 groups of experiments. For the 36 groups of isosteres (ignoring the difference of the specific experiments), in the similarity assessment of the tribological performance, the results are as follows: (1) within a $\pm 1 \%$ of deviation, there are six groups ( $16.67 \%$ of the experiments); (2) within a $\pm 5 \%$ deviation, there are 19 groups $(52.78 \%$ of the experiments); (3) within a $\pm 10 \%$ deviation, there are 27 groups (75.00\% of the experiments); (4) there are six groups with absolute values of deviation greater than $15 \%$ (13.89\% of the experiments); (5) there are 12 experiment groups (16.67\% of the experiments) with a friction-reduction or anti-wear performance that was consistent with or better than that of the template molecules.

In regards to both friction-reduction and anti-wear performance, of the 18 isosteres in the tribological performance study, there are four isosteres $(22.22 \%$ of all the isosteres), that exhibit consistent or better performance than that of the template molecules.

Relative to the template molecule, both frictionreduction and anti-wear performances largely improved as shown in Figs. 35(a)-(c).

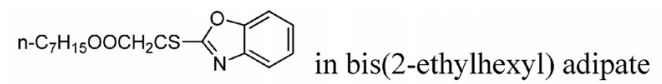

(a) $15.82 \%$ increase in the anti-wear effect and a $4.45 \%$ increase in the friction-reduction effect.

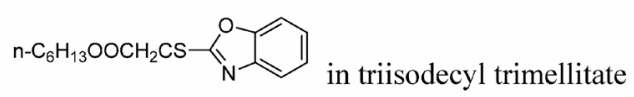

(b) $9.09 \%$ increase in the anti-wear effect and a $3.68 \%$ increase in the friction-reduction effect.

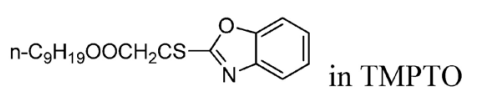

(c) $6.31 \%$ increase in the anti-wear effect and a $6.08 \%$ increase in the friction-reduction effect.

Fig. 35 The structural formula of the compound. 


\subsubsection{Best isosteres for the various lubricant base oils}

In bis(2-ethylhexyl) adipate, the Fig. 36 isostere is the optimal additive. The width of the wear scar was $0.808 \mathrm{~mm}$ and the friction coefficient was 0.1193 . The friction coefficient was not the lowest because that of the template molecule was relatively high.

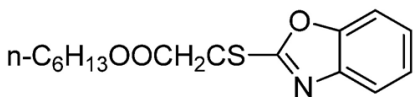

Fig. 36 The structural formula of the compound.

In triisodecyl trimellitate, the Fig. 37 isostere is the appropriate additive because the width of the wear scar was $0.472 \mathrm{~mm}$ and the friction coefficient was 0.0946. Although the anti-wear performance was not very good, the tribological properties were excellent because the template molecule performed adequately.

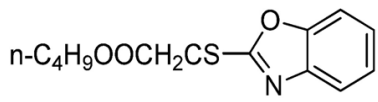

Fig. 37 The structural formula of the compound.

In TMPTO, the Fig. 38 isostere is the suitable additive. The width of the wear scar was $0.812 \mathrm{~mm}$ and the friction coefficient was 0.1086 .

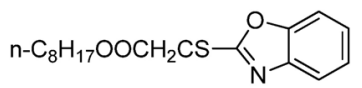

Fig. 38 The structural formula of the compound.

Although the resulting tribological properties of the screened isosteres in the corresponding lubricant base oils are not optimal, the purpose of the isostere molecular design was achieved, that is to say, the sulfur content was reduced and the resulting compounds displayed excellent comprehensive tribological properties within the same group.

\subsection{Feasibility of isostere molecular design}

\subsubsection{Thiobenzothiazole compounds}

Within a $\pm 5 \%$ deviation for the anti-wear effect, there are 11 molecules (30.56\% of the isosteres) while there are 17 isosteres ( $47.22 \%$ of the isosteres) within a $\pm 5 \%$ deviation for the friction-reduction effect. Within a $\pm 5 \%$ deviation for either the anti-wear effect or frictionreduction effect, there were 28 experiment groups
(38.89\% of all groups). If we assume that the good isosteres were those that are within a $\pm 5 \%$ deviation, the lowest proportion of the data for the three groups is then $30.56 \%$.

\subsubsection{2-benzothiazole-S-carboxylic acid esters}

Within a $\pm 5 \%$ deviation for the anti-wear effect, there were five molecules (27.78\% of the isosteres) while there were 14 isosteres (77.78\% of the isosteres) within a $\pm 5 \%$ deviation for the friction-reduction effect. Within a $\pm 5 \%$ deviation for either the anti-wear effect or friction-reduction effect, there were 19 experiment groups (52.78\% of all experiments). If we assume that the good isosteres are those that are within a $\pm 5 \%$ deviation, the lowest proportion of the data for the three groups is then $27.78 \%$.

Ignoring the specific molecular structure, for a deviation within a $\pm 5 \%$ deviation, the ratio of the isosteres is about $30 \%$. If a template molecule with better tribological properties is found, it could then be assumed that better isostere additive molecules will follow.

Isosteric design is a new development of the authors' previous QSTR work and it tries to use isosteres to mimic the template compound. Like the isosteric applications in the pharmaceutical field, the triboability of the isosteres may be increased, weakened, or yield an adverse effect. This is the reason why wear scar widths and the friction coefficients that have been reported are relatively greater than those from the results obtained from traditional additives. For this works' research, however, and relative to the template molecules, about $30 \%$ of the isosteres exhibited satisfactory tribological performance (only $\pm 5 \%$ deviations). In addition, some isosteres even improved both friction-reduction and anti-wear performances by a large amount. The absolute performance of the compounds currently obtained may not be satisfactory, but it is possible to achieve the excellent performance required after further optimization.

\subsection{Effect of isostere follow-up related to the base oil}

$\mathrm{S}, \mathrm{O}$, and $\mathrm{NH}$ group entities are considered classic cases of bivalent isosterism, and replacement could induce variations in terms of size, shape, electronic distribu- 
tion, chemical reactivity, lipophilicity, and hydrogen bonding capacity. Molecular structure modifications induce changes in tribological activity and mechanisms.

In Tables 1 and 2, it is seen that both the template and isostere molecules in the triisodecyl trimellitate base oil have very good tribological properties. It is an aromatic ester, whereas TMPTO and bis(2-ethylhexyl) adipate are aliphatic esters. In addition, the additive molecules are aromatic heterocyclic compounds. Hence, when the base oil and organic additives molecules are similar in structure, the tribological performance is very good.

\subsubsection{COMFA-QSTR and CoMSIA-QSTR models}

CoMFA and CoMSIA methodologies interpret the interaction between drug molecules and receptors, which depend on the difference in the molecular fields surrounding the compounds [31-35]. From this, in the previous research, it was assumed that the interaction between the lubricating medium and friction pairs had some correlation with the molecular fields from the lubricating medium. The friction pairs could "feel" the molecular field of the lubricant in order to achieve the expected tribological performance. With the assumption that the quantitative tribological relationship between lubricant molecules and friction pairs can be determined, the quantitative field parameters can be obtained and the regression analysis can be calculated when the lubricant molecules being compared are aligned in space and their molecular fields mapped to a 3D grid. The structures and the tribological data of different organic compounds, either as lubricant base oils or lubricant additives, were included in the CoMFA- and CoMSIA-QSTR models, respectively. The CoMFA-QSTR and CoMSIA-QSTR models suggest that changes in tribological activity strongly correlate with changes in the molecular force fields of the base oils or organic additives [28, 29].

In fact, the total molecular force field of the lubricant is determined by the interaction of the individual molecular force fields from the lubricant additives and base oils. For this study, the relationship between the tribological performance and the synergetic effect of the molecular force field between lubricant additive and base oil was further studied. CoMFA and CoMSIA prediction models of lubricant additive for the tribological performance were set up, and base oil as reference would be embedded in the contour maps, respectively.

\subsubsection{Synergetic effect of the molecular force field between the lubricant additive and base oil for anti-wear}

Figures 39-41 presents the CoMSIA contour diagrams of the lubricant additive for wear with an embedded base oil (triisodecyl trimellitate, bis(2-ethylhexyl) adipate, or TMPTO) as reference for both steric and electrostatic fields, respectively. In Figs. 39-41, the contours in green indicate the portion of the molecule where steric bulk is favored for wear while the yellow contours represent the reduction in wear performance of the molecules, and the contours in blue show where positive charge is favored for wear while the red region suggest where negative charge is favored for wear.

In Fig. 39, the relatively greater volume distribution of triisodecyl trimellitate is concentrated in or around the yellow region, one electronegative oxygen atom appears in the blue positions, and one carbon atom with a partial positive charge emerges in a red position. Figure 39 illustrates that it has good consistency with the molecular force field of additives and base oil, and this is the reason why the template molecules and isosteres in triisodecyl trimellitate exhibit very good anti-wear properties.

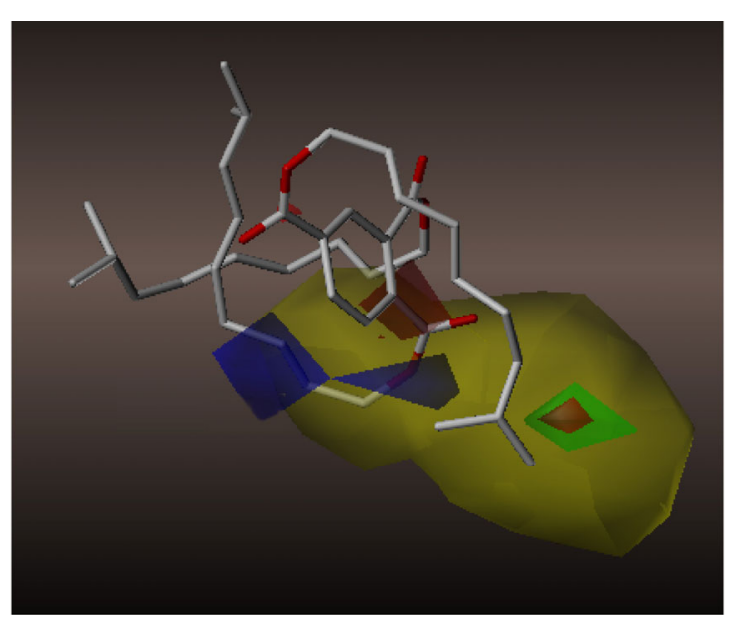

Fig. 39 CoMSIA contour diagram for wear with embedded triisodecyl trimellitate as reference for both steric and electrostatic fields. Green and yellow regions show where steric bulk is favored and disfavored, respectively. Blue region shows where positive charge is favored while red region shows where negative charge is favored. 
Comparing Fig. 40 with Fig. 39, less steric bulk appears in the yellow positions, and one electronegative atom $\mathrm{O}$ is present in a red position. This indicates a poor coordination of the molecular field of the additives and base oil. In addition, this indicates that the anti-wear activity of the system is not suitable when employing bis(2-ethylhexyl) adipate as base oil.

Figure 41 shows that more steric bulk appears in or around the yellow positions, suggesting that the molecular structure will benefit the anti-wear activity due to the synergistic effect of the steric field of the additives and base oil. However, one electronegative oxygen atom and one ester group appear in the red positions, and one carbon atom with a partial positive charge emerges in a blue position. This means that

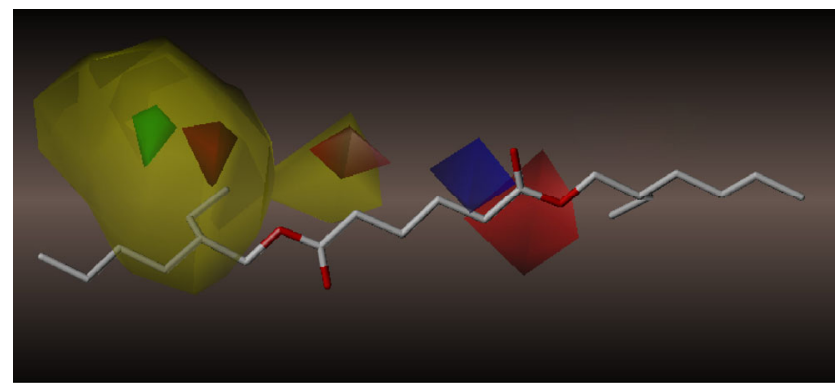

Fig. 40 CoMSIA contour diagram for wear with embedded bis(2ethylhexyl) adipate as reference for both steric and electrostatic fields. Green and yellow regions show where steric bulk is favored and disfavored, respectively. Blue region shows where positive charge is favored while red region shows where negative charge is favored.

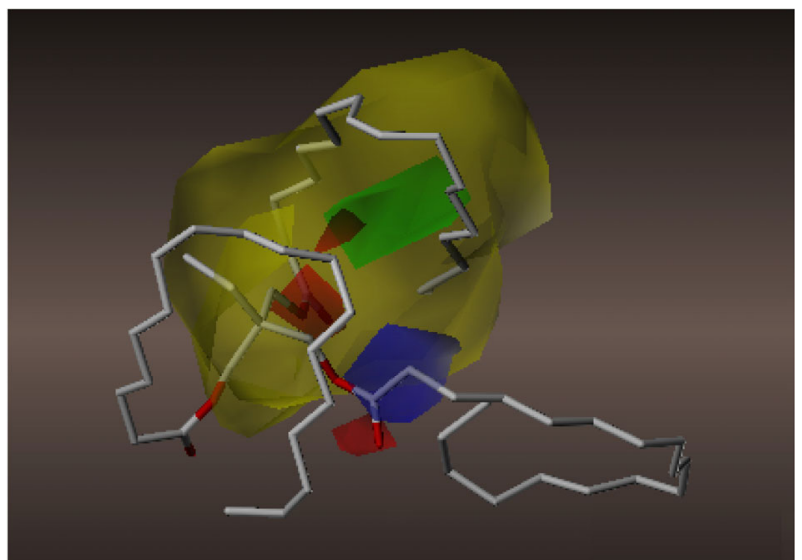

Fig. 41 CoMSIA contour diagram for wear with embedded TMPTO as reference for both steric and electrostatic fields. Green and yellow regions show where steric bulk is favored and disfavored, respectively. Blue region shows where positive charge is favored while red region shows where negative charge is favored. the polar groups or atoms do not present themselves in the appropriate positions and that the anti-wear performance of the lubricant is relatively poor when using TMPTO as a base oil.

\subsubsection{Synergetic effect of the molecular force field between the lubricant additive and base oil for friction- reduction}

The contour diagrams of lubricant additive are provided for friction with embedded base oils triisodecyl trimellitate, bis(2-ethylhexyl) adipate, or TMPTO as reference in Figs. 42-44, respectively. The contours for the steric field are in Figs. 42 and.44, wherein the green color indicates the portion of the molecule where steric bulk is favored for friction and the yellow contours represent the reduction in friction performance of the molecules. The contours for both steric and electrostatic fields are shown in Fig. 43. Here, the contours in green indicate the portion of the molecule where steric bulk is favored for friction while the yellow contours represent the friction-reduction performance of the molecules, and the contours in blue show where a positive charge is favored for friction while the red region show where a negative charge is favored for friction. Figure 42 highlights the good synergistic effect of the steric field with lubricant additives and base oil. The friction-reduction activity of the lubricant is good when triisodecyl trimellitate was employed as the lubricating base oil. Comparing Fig. 44 with Fig. 42, relatively less steric bulk emerges in the yellow

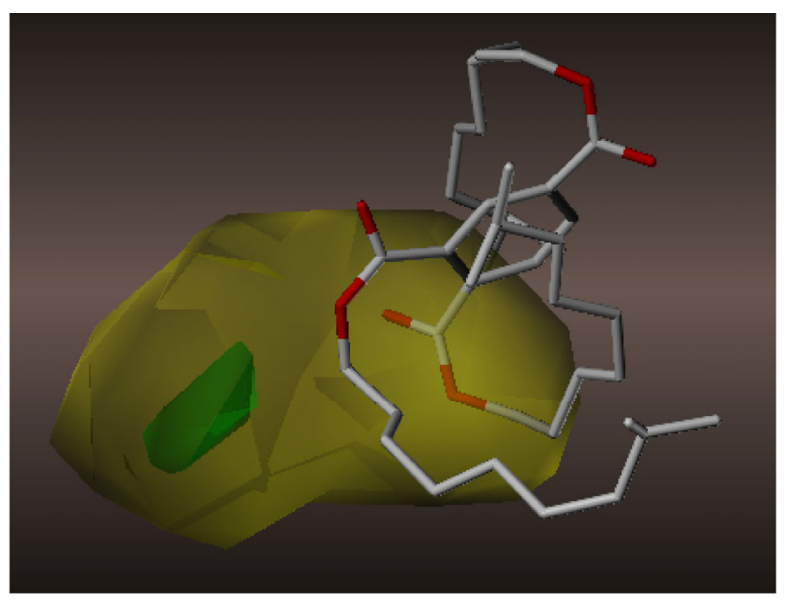

Fig. 42 CoMSIA contour diagram for friction with embedded triisodecyl trimellitate as reference for steric field. Green and yellow regions show where steric bulk is favored and disfavored, respectively. 


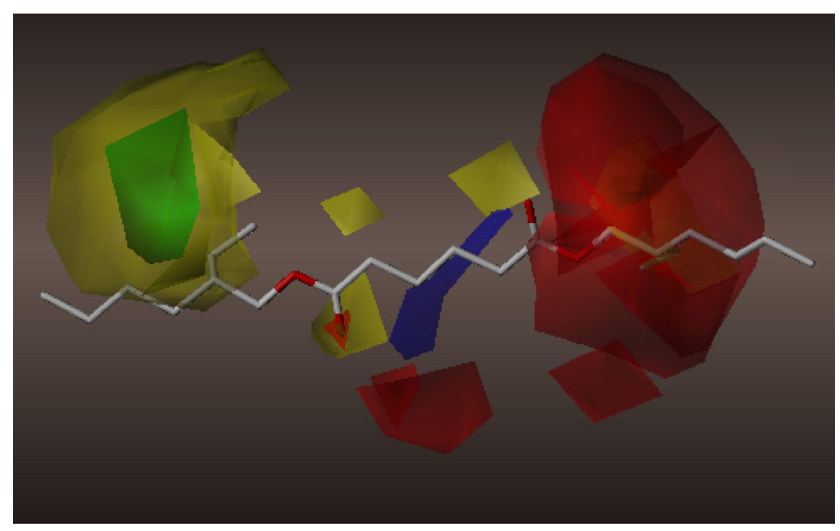

Fig. 43 CoMFA contour diagram for friction with embedded bis(2ethylhexyl) adipate as reference for both steric and electrostatic fields. Green and yellow regions show where steric bulk is favored and disfavored, respectively. Blue region shows where positive charge is favored while red region shows where negative charge is favored.

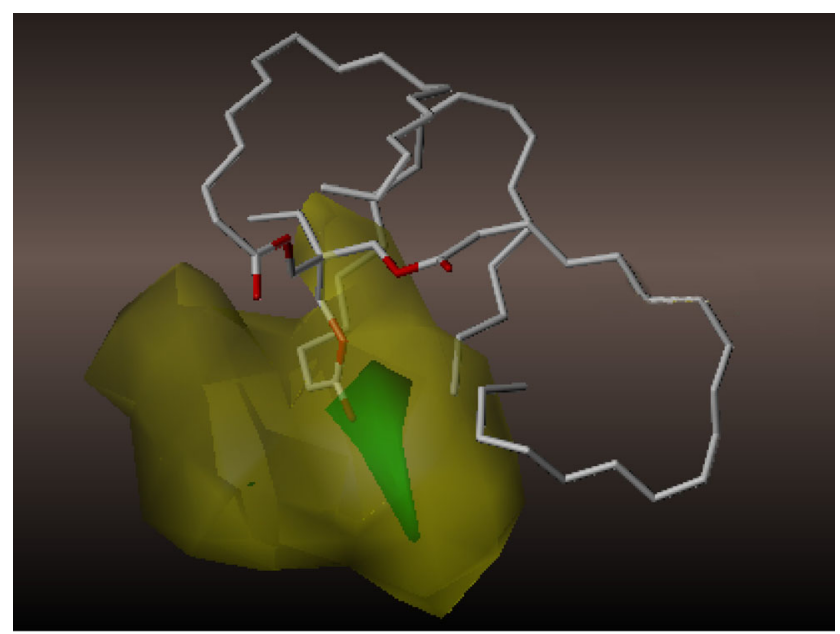

Fig. 44 CoMSIA contour diagram for friction with embedded TMPTO as reference for steric field. Green and yellow regions show where steric bulk is favored and disfavored, respectively.

positions, indicating that the friction-reduction performance of the lubricant (TMPTO as base oil) is not good enough. In Fig. 43, less steric bulk appears in the yellow positions and one electronegative oxygen atom and one ester group appear in or near red positions. This implies that the molecular force fields between the lubricant additive and base oil contradict each other and that the friction-reduction performance of the lubricant is relatively poor when using bis(2ethylhexyl) adipate as the base oil.

The analysis results of the six figures are consistent with the anti-wear or friction-reduction experimental results. The models suggest that the tribological properties are related to the synergetic effect of the molecular force fields of the organic additives and base oils. Comparing the three base oils, triisodecyl trimellitate has greater structural similarities to organic additives molecules than TMPTO and bis(2-ethylhexyl) adipate. This is because triisodecyl trimellitate is an aromatic ester while TMPTO and bis(2-ethylhexyl) adipate are aliphatic esters and because the additive molecules are aromatic heterocyclic compounds. In the experimental results, it can be seen that both the template and isostere molecules in the triisodecyl trimellitate base oil have very good tribological properties. Hence, when the base oil and organic additives molecules are similar in structure, a good synergetic effect of the molecular force field results. Thus, it can be assumed that for higher structural similarities, the molecular force fields are more synergic and that the corresponding lubricants will synergistically improve the tribological properties. The CoMFA and CoMSIA studies also imply that the models would be helpful in discovering appropriate lubricant base oils for the specified additives.

\subsubsection{BPNN-QSTR, EVA-QSTR and BRNN-QSTR models}

We also found during the BPNN-QSTR studies that some processes, such as the diffusion of additive molecules in base oil, have important effects on lubrication under low loads (e.g., $98 \mathrm{~N}$ ) [23-25]. This is due to the relatively thick base oil layer between the friction pair. Moreover, higher structural similarities of the additive and base oil molecules also lead to easier diffusion. Structural similarity is therefore a positive enhancement for tribological performance.

For the EVA-QSTR work, the results show that when liquid paraffin was employed as the base oil, the effect of heteroatom replacement in the aromatic ring on EVA spectra was very small, as was also their modifying contribution to the tribological performance [26]. Moreover, because the EVA descriptor is used to calculate rotational energy levels of a three-dimensional (3-D) conformation, the aromatic ring can be regarded as a rigid system with restricted bond rotation motion. However, the test results in this work demonstrated 
that when an ester was used as the base oil, heteroatom replacements in the aromatic ring have a relatively large effect on the tribological properties. The reason may lie in the differing tribological mechanisms between polar additives that are dissolved in non-polar liquid paraffin as opposed to being dissolved in polar esters. There are no changes in charge, polarity, or electrostatic fields in a non-polar base oil, whereas changes in a polar base oil can affect the interaction with polar additives and polar base oil. Changes in an aromatic heterocyclic ring can affect the tribological properties of an ester base oil. Therefore, in future modeling studies, it will be necessary to choose reasonable parameters corresponding to different base oils. For example, for a strong electrostatic field correlation between base oils and organic additives, relevant quantum descriptors in regards to charge and electric field distributions should be introduced. In fact, EVA is used to predict rotational infrared (IR) spectra. The EVA descriptor only yields changes in chemical bonding only for a 3-D conformation. In addition, while it can give a more accurate description of the fine features in the IR wavelength range it does not produce electric charge descriptions.

In the BPNN-QSTR or BRNN-QSTR model, some influential descriptors representing polarity characteristics of the molecules are introduced [27]. The dipole moment represents the molecular polarity whereas the quadrupole and octopole moments not only represent the orientation of polar molecules, but also how the molecules are related to charge in space. Spatial distributions of charge and electric fields have large surface effects on tribological processes. In future work, tribological features of different models for the same group of organic additive molecules in different base oils will be compared by the authors. Of particular importance are the intermolecular interactions between the base oil and the additives.

Moreover, tribology processes depend on the surface chemical reactions occurring under rubbing conditions and loading. Regrettably, previous isosteres study rarely involved surfaces, but our preliminary results show that it really works in the tribological research. Certainly, in the next optimization process, the surface reactions will be considered.

\section{Conclusions}

Based on the known chemical structures of lubricant additives, the design and synthesis of new structural analogs, or structure-related compounds, containing less sulfur have been identified with similar or improved tribological characteristics. Isosterism is an effective strategy for designing lubricant additives via molecular modification. Molecular modification also allows for the identification of template molecules that exhibit effective tribological characteristics, which minimizes synthetic efforts and, consequently, maximizes the potential successes for lubricant additives with reduced environmental risks.

By using the principle of isosterism, it is feasible to continue synthesizing compounds that exhibit optimal tribological performances. In future work by the authors, the sulfur atoms in the template molecule will be completely replaced and the sulfur-free frictionreduction and anti-wear lubricant additives will be evaluated. Because of the simple, effective, and intuitive features of isosterism, it is anticipated that it will be more widely used in tribology.

\section{Acknowledgments}

This project is supported by National Natural Science Foundation of China (Grant No. 51675395).

Open Access: The articles published in this journal are distributed under the terms of the Creative Commons Attribution 4.0 International License (http://creativecommons.org/licenses/by/4.0/), which permits unrestricted use, distribution, and reproduction in any medium, provided you give appropriate credit to the original author(s) and the source, provide a link to the Creative Commons license, and indicate if changes were made.

\section{References}

[1] Spikes H. Low- and zero-sulphated ash, phosphorus and sulphur anti-wear additives for engine oils. Lubrication Science 20(2): 103-136 (2008)

[2] Froeschmann R, Spruegel F. Sulfur and phosphorus bearing lubricant. U.S. Patent 3840 463, Oct. 1974 
[3] Gao F, Kotvis P V, Tysoe W T. The surface and tribological chemistry of chlorine- and sulfur-containing lubricant additives. Tribology International 37(2): 87-92 (2004)

[4] Zinke H, Lorenz J. Lubricant compositions containing sulfur-containing esters of phosphoric acid. U.S. Patent 4197 209, Apr. 1980

[5] Evans R D, More K L, Darragh C V, Nixonetal H P. Transmission electron microscopy of boundary-lubricated bearing surfaces. Part II: Mineral oil lubricant with sulfurand phosphorus-containing gear oil additives. Tribology Transactions 48(3): 299-307 (2005)

[6] Coyle C L, Greaney M A, Stiefel E I, Francis J N, Beltzeretal M. Molybdenum sulfur antiwear and antioxidant lube additives. U.S. Patent 4995 996, Feb. 1991

[7] DiBiase S A, Pialet J W. Sulfur-containing lubricant and functional fluid compositions. U.S. Patent 4800 031, Jan. 1989

[8] Love D, Schlicht R C, Biasotti J B. Lubricant additive. U.S. Patent 4765 918, Aug. 1988

[9] Malec R E. Lubricant composition of improved friction reducing properties. U.S. Patent 4201 684, May. 1980

[10] Thornber C W. Isosterism and molecular modification in drug design. Chemical Society Reviews 8(4): 563-580 (1979)

[11] Willett P, Barnard J M, Downs G M. Chemical similarity searching. Journal of Chemical Information and Computer Sciences 38(6): 983-996 (1998)

[12] Nikolova N, Jaworska J. Approaches to Measure Chemical Similarity-A review. Qsar \& Combinatorial Science 22(22): 1006-1026 (2004)

[13] Lima L M, Barreiro E J. Bioisosterism: a useful strategy for molecular modification and drug design. Current Medicinal Chemistry 12(1): 23-49 (2005)

[14] Patani G A, La Voi E J. Bioisosterism: A rational approach in drug design. Chemical Reviews 96(8): 3147-3176 (1996)

[15] Meanwell N A. Synopsis of some recent tactical application of bioisosteres in drug design. Journal of Medicinal Chemistry 54(8): 2529-2591 (2011)

[16] Brown N. Bioisosteres in Medicinal Chemistry. Methods \& Principles in Medicinal Chemistry. Weinheim (GER): WileyVCH, 2012

[17] Burger A. Isosterism and bioisosterism in drug design. In Progress in Drug Research. Basel (CH): Birkhauser, 1991: 287-371.

[18] Bhattacharya A, Singh T, Verma V K, Nakayama K. The role of certain substituted 2-amino-benzothiazolylbenzoylthiocarbamides as additives in extreme pressure lubrication of steel bearing balls. Wear 136(2): 345-357 (1990)

[19] Wan Y, Pu Q, Xue Q, Su Z. Antiwear and extreme pressure characteristics of 2-mercaptobenzothiazole derivative as the potential lubricating oil additive. Wear 192(1): 74-77 (1996)

[20] Zhang J, Liu W, Xue Q. Tribological properties of the film formed by 2-(n-dodecyldithio)-benzothiazole as additive in liquid paraffin. Wear 236(1): 34-38 (1999)

[21] Wu H, Fan K, Li J, Ren T, Ji K. Anti-wear performance and chemical property of films of nitrogen-containing heterocyclic lubricating oil additive. Acta Phys-Chim Sin 23(06): 911-915 (2007)

[22] Li Z, Li X, Zhang Y, Ren T, Zhao Y, Zeng X. Tribological study of a highly hydrolytically stable phenylboronic acid ester containing benzothiazolyl in mineral oil. Applied Surface Science 308: 91-99 (2014)

[23] Dai K, Gao X. Estimating Antiwear properties of lubricant additives using a quantitative structure tribo-ability relationship model with back propagation neural network. Wear 306(1-2): 242-247 (2013)

[24] Gao X, Wang Z, Zhang H, Dai K, Wang T. Quantitative Structure Tribo-ability relationship model for ester lubricant base oils. Journal of Tribology 137(2): 021801-1-021801-7 (2015)

[25] Gao X, Wang R, Wang Z, Dai K. BPNN-QSTR Friction model for organic compounds as potential lubricant base oils. Journal of Tribology 138(3): 031801-031801-8 (2016)

[26] Gao X, Wang Z, Zhang H, Dai, K. Three dimensional quantitative tribo-ability relationship model. Journal of Tribology 137(2): 021802-1-021802-8 (2015)

[27] Gao X, Dai K, Wang R, Wang Z, Wang T, He J. Establishing quantitative structure tribo-ability relationship model using Bayesian regularization neural network. Friction 4(2): 105-115 (2016)

[28] Gao X, Liu D, Wang Z, Dai K. Quantitative structure triboability relationship for organic compounds as lubricant base oils using CoMFA and CoMSIA. Journal of Tribology 138(3): 031802-031802-7 (2016)

[29] Liu D, Yang Q, Wang Y, Wang R, Dai K, He J. CoMFAQSTR and CoMSIA-QSTR models about N-containing Heterocyclic derivatives as lubricant additives about antiwear property. Tribology 36(4): 421-429 (2016)

[30] Liu D. The study on the synthesis and tribological properties of green antiwear lubricant additives. Master dissertation. Wuhan (China): Wuhan Polytechnic University, 2016

[31] Cramer R D III, Patterson D E, Bunce J D. Recent advances in comparative molecular field analysis (CoMFA). Prog Clin Biol 291: 161-165 (1989)

[32] Cramer R D. III, Patterson D E, Bunce J D. Comparative molecular field analysis (CoMFA). 1. Effect of shape on 
binding of steroids to carrier proteins. $J$ Chem Soc 110(18): 5959-5967 (1988)

[33] Kubinyi H, Folkers G, Martin Y C. 3D QSAR in Drug Design, Recent Advances. Berlin (GER): Springer Netherlands, 1998.

[34] Klebe G, Abraham U, Mietzner T. Molecular similarity indices in a comparative analysis (CoMSIA) of drug molecules

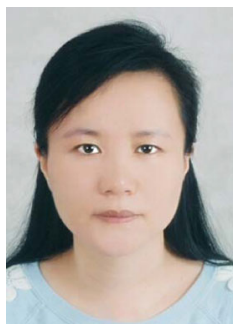

Xinlei GAO. She received her M.S. degree in 1996 from Huazhong Normal University in organic chemistry, and graduated from Wuhan Research Institute of Materials Protection in tocorrelate and predict their biological activity. J Med Chem 37(24): 4130-4146 (1994)

[35] Klebe G, Abraham U. Comparative molecular similarity index analysis (CoMSIA) to study hydrogen-bonding properties and to score combinatorial libraries. J Comput-Aided Mol Des 13: 1-10 (1999)

mechanical design and theory with Ph.D. degree in 2006. Currently she is a full professor at Wuhan Polytechnic University, member of Chinese Tribology Association. She is interested in tribology chemistry, chemical computing, and designation of lubricant. 